\title{
Erratum to: Exploitation of patchy soil water resources by the clonal vine Ficus tikoua in karst habitats of southwestern China
}

Chang-Cheng Liu • Yu-Guo Liu • Ke Guo •

Da-Yong Fan $\cdot$ Li-Fei Yu $\cdot$ Rui Yang

Published online: 7 September 2010

(C) Franciszek Górski Institute of Plant Physiology, Polish Academy of Sciences, Kraków 2010

\section{Erratum to: Acta Physiol Plant}

DOI 10.1007/s11738-010-0520-z

In the original publication, the unit of proline content has been expressed wrongly in the $y$-axis of Fig. 5c. It should be $\left(\mu \mathrm{g} . \mathrm{g}^{-1} \mathrm{DW}\right)$ instead of $\left(\mathrm{mg} . \mathrm{g}^{-1} \mathrm{DW}\right)$.

The online version of the original article can be found under doi:10.1007/s11738-010-0520-z.

C.-C. Liu · Y.-G. Liu · K. Guo $(\bowtie) \cdot$ D.-Y. Fan

State Key Laboratory of Vegetation and Environmental Change,

Institute of Botany, Chinese Academy of Sciences,

Beijing 100093, China

e-mail: guoke@ibcas.ac.cn

C.-C. Liu - Y.-G. Liu

Graduate University of Chinese Academy of Sciences,

Beijing 100049, China

L.-F. Yu $\cdot$ R. Yang

Forestry College, Guizhou University, Guiyang 550025, China 